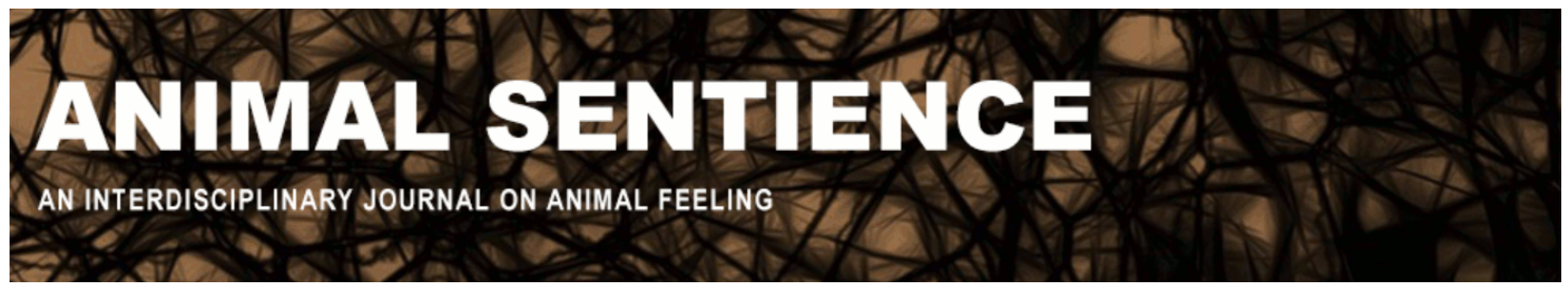

Walsh, Carolyn J. (2018) Lessons from behaviour for brain imaging. Animal Sentience 22(7)

DOI: $10.51291 / 2377-7478.1335$

Date of submission: 2018-05-25

Date of acceptance: $2018-05-30$

(c) (†)

This article has appeared in the journal Animal

Sentience, a peer-reviewed journal on animal

cognition and feeling. It has been made open access,

free for all, by WellBeing International and deposited

in the WBI Studies Repository. For more information,

please contact

wbisr-info@wellbeingintl.org.

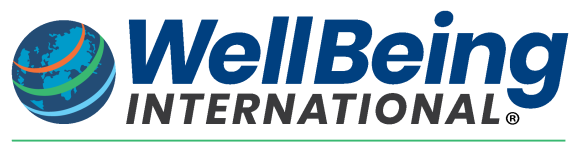

SOLUTIONS FOR PEOPLE, ANIMALS AND ENVIRONMENT 


\title{
Lessons from behaviour for brain imaging
}

Commentary on Cook et al. on Dog Jealousy

\author{
Carolyn J. Walsh \\ Department of Psychology \\ Memorial University of Newfoundland
}

\begin{abstract}
Integrating physiological and behavioural arousal with social context is fundamental to understanding affect in dogs. Cook et al. (2018) have made a worthy start towards illuminating the neural basis of dog affect underlying resource loss. However, their study depends on retrospective behaviour reports versus direct testing, and an interpretation of differential neural activation that is based on too few dogs. Research groups conducting canine brain-imaging work might: (1) consider collaborative approaches to augment sample sizes and replicability, and (2) take a recent lesson from dog behavioural research regarding a more cautious approach to applying functional labels to physiological and/or behavioural arousal.
\end{abstract}

Carolyn J. Walsh is an Associate Professor of Psychology and CoChair of the Cognitive and Behavioural Ecology Program at Memorial University of Newfoundland. She studies the relationships among social behaviour, physiology, cognition, and individual differences (personality) in birds and mammals, with a particular interest in dogs. She is the PI for the Canine Research Unit (CRU). play.psych.mun.ca/cru

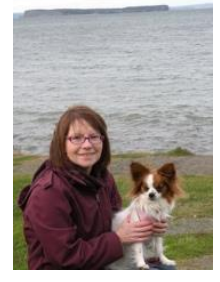

Cook et al. (2018) have shown that dogs reported by their owners to exhibit aggression towards unfamiliar dogs have greater amygdala activation when they see their owner giving a treat to a fake dog compared to seeing the owner dropping a treat into a bucket. The authors carefully suggest that this transient amygdala activation (it disappears after 30 trials) may represent jealousy.

This study's method is to be lauded as one of the ways in which we might make progress towards understanding the neurobiological basis of emotion in a socially complex non-human species such as the dog. This approach is championed in an earlier writing by the first author (Cook 2017):

“... as scientists, we shouldn't ask whether dogs feel about us as we feel about them. Nor should we focus solely on the expression of emotion. Instead we should ask how dogs use valenced representations of peripheral body states to inform decision-making and learning, and in what situations these processes become engaged." (p. 2; emphasis is mine)

This excerpt succinctly summarizes the rationale for the target study. Simulating a context in which a resource (treat) is lost to a social competitor (fake dog) versus a non-social object (bucket) by a valued social resource/attachment figure (owner) allows Cook et al. to examine the location of differential brain activation (amygdala) and relate what is known about neuroanatomical function to the dog's past behaviour (conspecific aggression). 
Context, behaviour, individual differences, and physiological arousal must be intimately intertwined with affect and cognition. In my canine research, we have examined the relationships between hormones, behaviour, and canine personality in social contexts (e.g., Ottenheimer Carrier et al., 2013; Walsh et al., 2014). As suggested by Cook (2017), there is not always a close coupling of "peripheral body states" (e.g., HPA activation/cortisol release) and "the expression of emotion" (e.g., behaviour or musculoskeletal changes). In our work, salivary cortisol increases when dogs interact in a dog park. Does this indicate arousal with a negative valence, that is, "bad" stress or fear? or arousal with a positive valence, as may occur during rewarding social interactions, for example, play? Observing different behaviours (hunched posture vs. play) and knowing whether the park and/or other dogs present (i.e., the context) is familiar to the dog can help us differentiate the two possibilities. In fact, the effect of individual differences in personality traits, specifically, neuroticism, on arousal also emerges when context (familiarity) is evaluated. Disentangling the impacts of these various factors is necessary to understand the experiences of individual dogs and even, perhaps, their welfare.

So, while we should not focus solely on "expressions of emotion" to indicate an affective state, neither should we depend solely on physiology. Examining behaviour in conjunction with physiological states gives us the best chance of correctly identifying the factors that shape responses to particular contexts or events. This approach is partially incorporated by Cook and his collaborators, as they use an owner-based retrospective inventory of each dog's behaviour, the C-BARQ (Hsu \& Serpell, 2003). As we know, the best predictor of an individual's future behaviour is their past behaviour. In this light, the C-BARQ is a measure of a dog's behavioural tendencies or temperament. However, a reported history of no unfamiliar dog aggression could reflect limited opportunity for such behaviours, inhibition of aggression due to incompatible learned/trained behaviours, and/or predisposition for activation of other neuroendocrine systems during interactions with unfamiliar dogs. If amygdala activation in the context of the study's fake dog scenario could predict future aggression in dogs who have not shown such behaviours to date, then the authors are on to something. Unfortunately, there was no direct behavioural testing of the study dogs (e.g., by evaluating their responses to the owner feeding a [different?] fake dog when they were not in the fMRI). Cook et al.'s case for a relationship between dog-directed aggression and amygdala activation would be strengthened if dogs with no history of aggression, along with positive differential amygdala activation, actually showed aggression in such a test. But what if aggression in the test was shown by dogs without positive amygdala activation? We do not have these answers, because this test has not yet been reported (or, perhaps, conducted).

The need for cautious interpretation of these data and further testing is clear; only 7 of 13 dogs had any history of dog-directed aggression to unfamiliar dogs (i.e., a score on the C-BARQ sub-scale greater than zero, see Figure 2 in the target article). Of these 7 dogs, a mere five showed a positive differential average amygdala activation, that is, more activation to the feeding of the fake dog than to the dropping of a treat in the bucket. Notably, the dog with the greatest amygdala activation (mean value $=1.28$ ) had no reported dog-directed aggression at all (but might exhibit it, given an appropriate test context).

We can understand why small sample sizes are a problem for canine brain-imaging studies in general (Andics et al., 2016; Berns \& Cook, 2016). It is not easy to train dogs to tolerate fMRI, and samples for individual studies will likely always be hard-won and smallish. Not only do we 
need more studies and more trained dogs to encompass broader individual differences, but we need to ensure that a range of important behavioural tests are carried out on the dogs for whom we have brain-imaging data. No small tasks here! However, recent collaborative approaches to replicating results and obtaining larger sample sizes (e.g., the Psychological Science Accelerator, Chartier et al., 2018) might be very useful for this type of research.

As to the current study, the authors readily admit that more work is needed. But even should their findings be convincingly replicated, would labelling the relationship as the complex emotion "jealousy" be useful?

The study of emotion is not my expertise, so I leave the nuances of this argument to others. However, recent work on two overt behaviours in dogs - the "roll-over" (Norman et al., 2015) and the "play bow" (Byosiere et al., 2016) - may be instructive. In both cases, these common dog behaviours have been assigned a priori to functional categories (i.e., as signals of submission and meta-communication, respectively). The recent studies, through painstaking behavioural observation and hypothesis testing, have caused us to re-evaluate and update these views. Indeed, such behaviours can have multiple functions, depending on the context in which they occur (e.g., play vs. fighting, Smuts et al., 2015). Errors in recognizing that canine roll-overs do not necessarily reflect submission (as in Adolphs, 2017) could lead to flawed interpretations about the affect underlying this behaviour. A clear empirical understanding of the dog behaviours being evaluated is critical before discerning their underlying motivations or affect. My colleagues and I argue that a motivationally neutral approach to the initial assessment and labelling of all dog behaviour (and, by extension, associated emotion) is required to avoid conflating form and function, or description and inference (Howse et al., 2018; see also the classic advice of Martin \& Bateson, 2007; Moran \& Fentress, 1979). Importantly, this approach does not preclude the emergence of functional explanations from the relationships among (convincing amounts of) empirical data. However, in my view, even careful imposition of premature labels on physiological or behavioural arousal is probably unwise, since they may turn out to be insufficient or simply incorrect.

\section{References}

Adolphs, R. (2017) Dogs consciously experience emotions: The question is, which? Animal Sentience 14(2).

Andics, A., Gábor, A., Gásci, M., Faragó, T., Szabó, D., \& Miklósi, Á. (2016) Neural mechanisms for lexical processing in dogs. Science 353(6303): 1030-1032.

Berns, G.S., \& Cook, P.F. (2016) Why did the dog walk into the MRI? Current Directions in Psychological Science 25(5):363-369.

Byosiere, S.-E., Espinosa, J., \& Smuts, B. (2016) Investigating the function of play bows in adult pet dogs. Behavioural Processes 125: 106-113. 
Chartier, C., McCarthy, R., \& Urry, H. (2018) The psychological science accelerator. Observer $31(3): 23-24$.

Cook, P.F. (2017) Studying dog emotion beyond expression and without concern for feeling. Animal Sentience 14(15).

Cook, P., Prichard, A., Spivak, M., \& Berns, G.S. (2018) Jealousy in dogs? Evidence from brain imaging. Animal Sentience 22(1).

Howse, M.S., Anderson, R.E., \& Walsh, C.J. (2018) Social behaviour of domestic dogs (Canis familiaris) in a public off-leash dog park. Behavioural Processes.

Hsu, Y., \& Serpell, J.A. (2003) Development and validation of a questionnaire for measuring behavior and temperament traits in pet dogs. Journal of the American Veterinary Association 223(9): 1293-1300.

Martin, P.R., \& Bateson, P. (2007) Measuring Behaviour: An Introductory Guide, 3rd edition. Cambridge University Press, Cambridge.

Moran, G. \& Fentress, J.C. (1979) A search for order in wolf social behaviour. In: Klinghamer, E. (Ed.), The Behaviour and Ecology of Wolves. Garland STPM Press, pp. 245-283.

Norman, K., Pellis, S., Barrett, L., \& Henzi, S.P. (2015) Down but not out: Supine postures as facilitators of play in domestic dogs. Behavioural Processes 110: 88-95.

Ottenheimer Carrier, L., Cyr, A., Anderson, R.E., \& Walsh, C.J. (2013) Exploring the dog park: Relationships between social behaviours, personality and cortisol in companion dogs. Applied Animal Behaviour Science 146: 96-106.

Smuts, B., Bauer, E., \& Ward, C. (2015) Rollovers during play: Complementary perspectives. Behavioural Processes 116: 50-52.

Walsh, C.J., Anderson, R.E., Ottenheimer Carrier, L., Penney, J., \& Croucher, K. (2014) Canine salivary cortisol in frequent dog park visitors is predicted by individual differences in Neuroticism (MCPQ-R). Journal of Veterinary Behavior: Clinical Applications and Research 9: e14. 


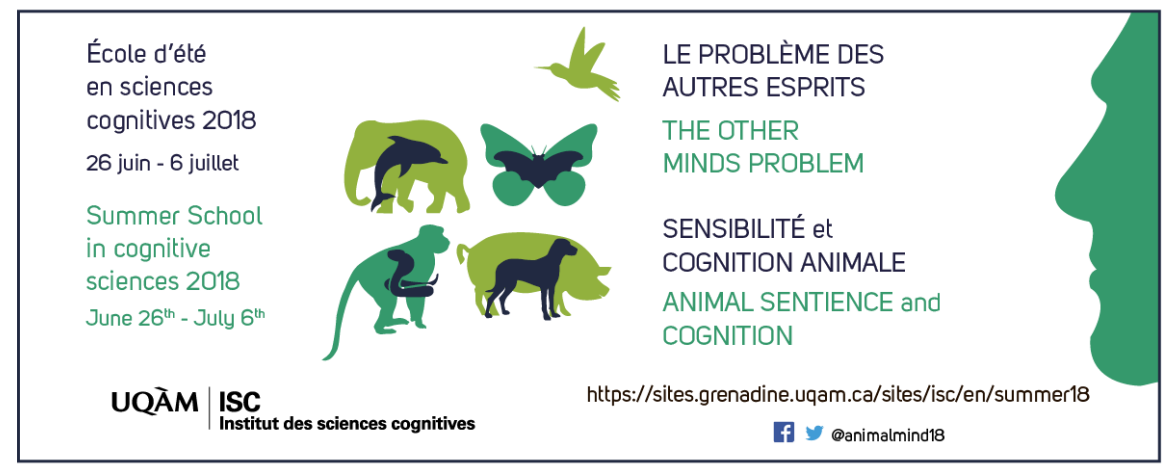

\title{
ISC 2018 Summer School in Cognitive Sciences
}

\author{
June 26 - July 6, 2018 \\ Montreal (Canada) \\ The Other Minds \\ Problem: Animal \\ Sentience and Cognition
}

Overview. Since Descartes, philosophers know there is no way to know for sure what — or whether — others feel (not even if they tell you). Science, however, is not about certainty but about probability and evidence. The 7.5 billion individual members of the human species can tell us what they are feeling. But there are 9 million other species on the planet $(20$ quintillion individuals), from elephants to jellyfish, with which humans share biological and cognitive ancestry, but not one other species can speak: Which of them can feel — and what do they feel? Their human spokespersons - the comparative psychologists, ethologists, evolutionists, and cognitive neurobiologists who are the world's leading experts in "mindreading" other species - will provide a sweeping panorama of what it feels like to be an elephant, ape, whale, cow, pig, dog, chicken, bat, fish, lizard, lobster, snail: This growing body of facts about nonhuman sentience has profound implications not only for our understanding of human cognition, but for our treatment of other sentient species.

Gregory Berns: Decoding the Dog's Mind with Awake

Neuroimaging

Gordon Burghardt: Probing the Umwelt of Reptiles

Jon Sakata: Audience Effects on Communication Signals

PANEL 1: Reptiles, Birds and Mammals

WORKSHOP 1: Kristin Andrews: The "Other" Problems: Mind, Behavior, and Agency

Sarah Brosnan: How Do Primates Feel About Their Social Partners?

Alexander Ophir: The Cognitive Ecology of Monogamy Michael Hendricks: Integrating Action and Perception in a Small Nervous System

PANEL 2: Primates, Voles and Worms

WORKSHOP 2: Jonathan Birch: Animal Sentience and the Precautionary Principle

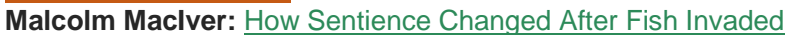
Land 385 Million Years Ago

Sarah Woolley: Neural Mechanisms of Preference in Female Songbird

Simon Reader: Animal Social Learning: Implications for Understanding Others

PANEL 3: Sea to Land to Air

WORKSHOP 3: Steven M. Wise: Nonhuman Personhood

Tomoko Ohyama: Action Selection in a Small Brain (Drosophila Maggot)

Mike Ryan: "Crazy Love": Nonlinearity and Irrationality in Mate Choice

Louis Lefebvre: Animal Innovation: From Ecology to

Neurotransmitters

PANEL 4: Maggots, Frogs and Birds: Flexibility Evolving SPECIAL EVENT: Mario Cyr: Polar Bears

Colin Chapman: Why Do We Want to Think People Are

Different?

Vladimir Pradosudov: Chickadee Spatial Cognition

Jonathan Balcombe: The Sentient World of Fishes

PANEL 5: Similarities and Differences

WORKSHOP 5 (part 1): Gary Comstock: $\underline{\text { A Cow's Concept of }}$ Her Future

WORKSHOP 5 (part 2): Jean-Jacques Kona-Boun: $\underline{\text { Physical }}$

and Mental Risks to Cattle and Horses in Rodeos

\author{
Joshua Plotnik: Thoughtful Trunks: Application of Elephant \\ Cognition for Elephant Conservation \\ Lori Marino: Who Are Dolphins? \\ Larry Young: The Neurobiology of Social Bonding, Empathy and \\ Social Loss in Monogamous Voles \\ Panel 6: Mammals All, Great and Small \\ WORKSHOP 6: Lori Marino: The Inconvenient Truth About \\ Thinking Chickens \\ Andrew Adamatzky: Slime Mould: Cognition Through \\ Computation \\ Frantisek Baluska \& Stefano Mancuso: What a Plant Knows \\ and Perceives \\ Arthur Reber: $\mathrm{A}$ Novel Theory of the Origin of Mind: \\ Conversations With a Caterpillar and a Bacterium \\ PANEL 7: Microbes, Molds and Plants \\ WORKSHOP 7: Suzanne Held \& Michael Mendl: Pig Cognition \\ and Why It Matters \\ James Simmons: What Is It Like To Be A Bat? \\ Debbie Kelly: Spatial Cognition in Food-Storing \\ Steve Phelps: Social Cognition Across Species \\ PANEL 8: Social Space \\ WORKSHOP 8: To be announced \\ Lars Chittka: The Mind of the Bee \\ Reuven Dukas: Insect Emotions: Mechanisms and Evolutionary \\ Biology \\ Adam Shriver: Do Human Lesion Studies Tell Us the Cortex is \\ Required for Pain Experiences? \\ PANEL 9: The Invertebrate Mind \\ WORKSHOP 9: Delcianna Winders: Nonhuman Animals in \\ Sport and Entertainment \\ Carel ten Cate: Avian Capacity for Categorization and \\ Abstraction \\ Jennifer Mather: Do Squid Have a Sense of Self? \\ Steve Chang: Neurobiology of Monkeys Thinking About Other \\ Monkeys \\ PANEL 10: Others in Mind \\ WORKSHOP 10: The Legal Status of Sentient Nonhuman \\ Species
}

